\title{
Research on Internet Education Poverty Alleviation in the Era of Big Data
}

\author{
Wanbing Shi ${ }^{1, \text { a, }}{ }^{*}$, Xiaoyue Zhang ${ }^{1}$ \\ ${ }^{1}$ School of Humanities and Law, Northeastern University, China. \\ awanbingshi@163.com
}

\begin{abstract}
Education promotes people's success through employment (entrepreneurship) after entering the workplace by promoting people's knowledge and skills. For the poor people, effective poverty alleviation through education can effectively cut off intergenerational transmission of poverty. Among the various poverty alleviation strategies, it is the most effective and practical one. Up to now, China's education poverty alleviation has made great progress, but there are still many practical difficulties, such as uneven distribution of quality education resources, unfair education, insufficient teachers, and poor rural populations. These difficulties are difficult to solve under the traditional education poverty alleviation model. Therefore, we need to innovate ways of poverty alleviation through education to improve the effectiveness of poverty alleviation. In the era of big data, the introduction of modern internet technologies to launch "Internet + education for poverty alleviation" can provide universal education for poor people across the country by providing precision education to help the poor. Therefore, this dissertation conducts research on how to achieve "Internet + education for poverty alleviation" in the era of big data. It points out the actual case of "Internet + education for poverty alleviation" that has been promoted, and points out that China's development of "Internet + education for poverty alleviation" still exists Hardware issues, research on the country's relevant landing policy of "Internet + education for poverty alleviation", and analysis of the realization of the "Internet + education poverty alleviation" realistic approach.
\end{abstract}

Keywords: Poverty alleviation through education; Internet and education for poverty alleviation; precision; era of big data.

\section{大数据时代下的互联网教育扶贫研究}

\section{史万兵 ${ }^{1}, \quad$ 张潇月}

\section{1. 东北大学文法学院，中国}

摘 要: 教育通过促进人们拓展知识、提升技能, 进入职场后通过就业（创业）一步步获取成 功的未来。对于贫困人口来说, 高效教育扶贫可以有效隔断贫困代际传递, 在诸多扶贫策略 当中, 是最有效也最实际的一个策略。发展到今天, 我国教育扶贫取得了很大进展, 但仍旧 存在许多现实性困难，例如优质教育资源分布不均衡、教育不公平、师资力量不足、贫困人 口分布偏远农村等等。在传统教育扶贫模式下, 这些困难很难解决。因此, 我们需要创新教 育扶贫方式来提升其扶贫成效。大数据时代引入现代网络技术开展 “互联网+教育扶贫” ，能 够通过提供精准教育扶贫达成面向全国贫困人群的普及性教育。因此, 本篇论文就大数据时 代如何实现 “互联网+教育扶贫” 开展研究，其中指出当前已经推进的“互联网+教育扶贫” 实际案例, 指出我国发展 “互联网+教育扶贫” 还存在的各种软硬件问题, 研究国家方面对“互 联网+教育扶贫”的相关落地政策，分析实现 “互联网+教育扶贫”的现实性途径。

\section{关键词：教育扶贫；“互联网+教育扶贫”；精准；大数据时代}

\section{1. 前言}

习近平总书记于 2016 年4月中旬的 “网络安全与信息化工作” 座谈会中提及要 “发挥互联网优 势来推进 “互联网+教育”, 同时推动互联网作用于脱贫攻坚, 让贫困孩子接受优质教育, 推 进 “精准扶贫”、“精准脱贫” ”。这一年来，各级教育部门持续发展 “互联网+教育” 这一 
精准教育扶贫计划, 通过互联网把优质教育资源送到贫困地区的贫困孩子, 满足他们对知识 的渴求，获得了很大的成效。

\section{2. 我国落实 “互联网+教育” 下的精准教育扶贫目标}

互联网时代, 全球教育体系结合互联网科技发生重大变化, 把 “互联网+教育” 引入教育扶贫 领域能够为面向我国贫困区域的贫困孩子提供更为精准的教育扶贫, 创新教育扶贫机制, 在 具体的教育扶贫举措 (工作) 中, “互联网+教育” 对教育扶贫提出了一些精准目标。我们需 要开展精准扶贫工作帮助贫困人口精准脱贫。在精准扶贫工作推进中, 教育扶贫也需要推进 精准教育扶贫。引入 “互联网+教育” 开展教育脱贫, 这就需要通过大数据对相关群体开展分 析，根据教育对象具体提供教育内容。对 “互联网+教育” 下的教育扶贫机制进行精准设计。 “互联网+教育” 下的教育扶贫, 需要基于《慈善法》框架, 精准设计相关的筹集资金方法、 渠道以及教育扶贫实施的详细组织流程, 同时也重视教育扶贫项目的具体评价标准, 在确定 一系列的科学设计机制情况下，搭建广泛的资金来源渠道。

\section{3. “互联网+教育扶贫” 的发展现状}

习近平总书记在多次关于扶贫工作的会议中不断强调 “扶贫必扶智” ，对于贫困地区、贫困 家庭的孩子来说, 让他们接受良好教育, 这是阻断 “贫困代际传递” 的十分重要途径, 也是 当前扶贫工作的重点。

传统支教模式需要志愿者带着行李到贫困地区, 而当前互联网的普及使得使用一根网线就可 以把志愿者和贫困地区学校连接起来, 大量的志愿者能够通过互联网帮助边远乡村学校学生, 补充乡村学校师资力量的不足。互联网具备天然的公平属性, 可以把供给优持资源的一方和 需求的一方有效连接在一起, 通过互联网、大数据等科技, 实现数字脱贫、教育扶智。通过 互联网和信息化设备的全覆盖, 意味着山沟里的孩子也能通过 “互联网+教育” 的实施接受优 质教育, 教育相关的社会团体、机构等, 能够通过四通八达的互联网为贫困地区学校提供推 进精准教育扶贫需要的产品和服务。同时, 还可以利用大数据技术的精准支持, 对不同区域 不同人群教育需求进行精准定位, 提升教育扶贫效率。

\section{4. 整合资源推进大数据时代的教育扶贫}

通过 “互联网+教育” 推进教育扶贫, 毫无疑问推进了教育扶贫使之向着精准扶贫方向发展, 起到了很大成效, 目前 “互联网+教育扶贫” 仍旧存在较多的问题需要解决。当前教育基础设 施建设是越建越好，相关的硬件问题，或者通过扶贫方法，或者通过政府投入，基本上得到 解决。但是, 通过调研却发现目前却存在一些现实性问题, 需要引起关注。比如贫困地区教 师自身水平存在问题、现代化设备被搁置不用和软硬件水平没有跟上等。针对以上存在问题, 考虑到当前 “互联网+教育” 的发展现状, 如何更好地发挥互联网的作用开展对贫困地区贫困 人群的帮扶, 确保教育扶贫能够取得实效。作者认为, 可以从以下方面着手, 努力解决当前 存在问题。

1). 做好基础设施建设。通过做好学校信息化建设相关的基础设施保障, 保证推进 “互联网+ 教育” 的相关硬件设施配套合乎网络教育要求, 依托现代化的信息化教育平台, 推进适合学 校学生需求的教育资源开发, 为贫困地区的中小学以及相关教学点, 设置优质的数字化教育 资源。

2). 培养线下的教师人才做到 “互联网+教育” 的线下有效保障。这是一个解决 “谁来教” 的 问题, 对于现有的教师开展相关的培训, 这种培训既可以通过线上平台开展有针对性的直面 教师团队的培训, 也可以由教育资源优质学校对接贫乏学校, 通过输送教师志愿者团队等, 前往贫困地区学校对当地教师开展面对面的教学培训等。 
3).建立长效帮扶机制保障 “互联网+教育” 推动教育扶贫工作有效开展。通过各个公益组织、 互联网企业、教育企业等的合作，推进互联网教育扶贫实践发展，立足于长远发展观点把 “互 联网+教育扶贫” 的目标确定为通过现代互联网教育产品和服务帮助学生脱离单纯的知识获取 学习方式、培育学生掌握更好学习方法以及习得分析信息、懂得如何输出知识利用知识等, 从而培育学生核心的学习技能。

4). 打造开放式的 “互联网+教育扶贫” 模式。推进 “互联网+教育扶贫” ，通过线上资源来教 育线下的学生, 特别需要注意教育目标的有效传递和达成。在开发相关的产品和服务时, 需 要重视其互动性的打造, 努力做到线上教学也可以像线下老师那样, 跟学生互动, 了解学生 真实需求。

\section{5. 结论}

教育扶贫是一项 “功在当代, 利在千秋” 的用知识改变贫困人群命运的伟大事业, 当前, 因 为受到各种客观条件限制, 优秀的教育资源不能惠及偏远的贫困地区。因此, 引入 “互联网+ 教育” , 通过线上畅通的互联网教育, 把优秀的教育资源输送到贫困地区, 解决教育资源不 公平情况, 这对于教育扶贫工作, 无非是一个重大利好消息。利用开创性的 “互联网+教育”, 引入大数据技术, 了解贫困地区人群对教育的需求, 有的放矢地打造对应的教学内容、教育 产品 (服务) , 培育需要的教师团队, 等等, 从而最大程度发挥优秀教育资源作用, 精准推 进教育扶贫工作使之在尊重客观现实的情况下得到超水平的效用。因此, “互联网+教育” 是 当代开展教育扶贫的有力举措, 沿着这一方向发展, 必然能够达成教育脱贫的目的。

\section{References}

[1]. Jiang Jibe (2016): “Xi Jinping hosted the Symposium on Cyber Security and Informationization", "People's Daily", April 20.

[2]. Zhang Yi (2016): China Poverty Alleviation and Development Report 2016: China's Poor Population Has Reduced 790 Million, International Online (Beijing), and December 27.

[3]. Anonymous (2016): Shill Town, Licheng District: “Internet + Distance Education" Helps Accurate Poverty Alleviation, Zhuozhou Pioneer Newspaper, November 1st.

[4]. Zhang Rontgen (2015): How to Accurately Poverty with Internet + Education, Nanfang Daily, October 20.

[5]. Zhang Dengue (2015): "Promoting the Internet + Accurate Poverty Alleviation", Science and Technology Daily, October 20.

[6]. Duane Weanling (2016): The Important Significance of Online Education in Poverty Alleviation, Education (Abstract), pp. 301-302.

[7]. Jiang Chen, Wang Bangui (2016): “An Analysis of the "Internet + Education" Poverty Alleviation Model Mechanism Construction", "Theory of Theory”, No. 4.

[8]. Liu Fang (2016): "The Road to Education Poverty Alleviation in Old Northern Shaanxi under the Background of Internet Plus", "Reading the World", Issue 7. 